\title{
Towards a Multi-modal Phenomenological Approach of Violence
}

\section{Cristian Ciocan ${ }^{1}$}

Published online: 8 July 2020

(c) Springer Nature B.V. 2020

Violence is a pervasive dimension of our individual and social existence. No one can deny such an evidence, precisely during these troubled times of social unrest. The unanimous feeling that we are living in an increasingly violent world, full of rage and anger, is more and more tormenting. Not only our past is full of violence as well as our present, but also we cannot have high expectations regarding a peaceful future. There is no need to mention the countless instances of violence worldwideeach one having its own grounds and simultaneously generating new violences, with their always-particular contexts and their multi-stratified implications-in order to enhance our "catastrophic sensitivity". Even for those who are somewhat sheltered from actual aggression, just seeing it on TV or Internet from a quasi-safe distance, violence is still an indisputable and a deeply disturbing menace. Indeed, any such circumstantially "sheltered" situation is by definition unstable and it can switch over, at any time, into its opposite. For even if, in the particular context we live in, violence is not an actual one (it happens "somewhere else," "out there," or to "someone else"), and even if it is not imminent (as in a perceptible and definite threat), violence is always latent and, as such, it can at any time re-emerge and suddenly explode in our face. In fact, existential and social peace seems to be only a very fragile crust, and it can at any moment be shattered by appalling crimes terrifying the public space, by street clashes of all kinds, by terrorist attacks, or by the horrors of war.

This latency of violence-a diffuse presence of a non-actuality-seems to constitute the special atmosphere in which our concerned thinking of violence takes place. More precisely, violence does not primarily challenge our thought when it is given as an actual event that we are currently confronting and dramatically experiencing in our lives, but rather when we understand it as a latent phenomenon, which, from its more or less diffuse presence, constantly menaces the erratic balance of our daily existence. For, in a "real" situation of violence, our main preoccupation would be rather to escape and survive ("how to evade violence," "how to get rid of the one

Cristian Ciocan

cristian.ciocan@unibuc.ro

1 University of Bucharest, Bucharest, Romania 
who attacks me"), and less to question the violence "in itself," in "what it is," "how it is," or "why it is what it is". It is in this sense that the pressing latency of violence (its eventuality and not its actuality) nourishes and sharpens our increasing reflective awareness of this phenomenon. This latency (experienced as a diffuse atmosphere, or as a climate of violence) is constituted by remembering past traumatic experiences, by diffuse anticipations or apprehensions of future violences, as well as by the multifarious imagistic givenness of violence. Thus, the first phenomenological difference to draw would not be that between violence and non-violence (or between violence and counter-violence, or between legitimate and illegitimate violence), but that between "latent violence" and "actual violence". And it is precisely the volatile dynamic of violence from latency to imminence and to actuality that accentuates, more and more, our pressing meditative concern regarding the phenomenology of violence. Accordingly, only when violence is not simply absent, but latent (a kind of "present absence" or an "absent presence"), can emerge the philosophical preoccupation to understand it, to decipher its code and, eventually, to explore its phenomenological structures, such as the genesis of the adversative intersubjectivity, the vulnerability of our embodiment, the inflammation of affectivity, its peculiar temporality, or its specific spatiality.

Moreover, beside all the obvious tensions that the various forms of violence generate in our concrete life-worlds, we can further ask if violence does not also involve a disturbing effect on the phenomenological conceptuality itself. This question pertains to the "phenomenal charge" of the violence itself, to its overwhelming givenness, and to its relation to the concepts that aim to grasp it and determine it. What if violence-as phenomenon_-proves to be a ferment that provokes a radical reworking and profound redefinition of the standard terminology of classical phenomenology? What if the very conceptuality framing our understanding of violence proves finally to be too weak to capture this phenomenon in its convoluted meanings and its multifarious phenomenal strata? Considering, for example, some basic classical phenomenological notions - such as ego and self, embodiment and affectivity, intersubjectivity and language, spatiality and temporality, being and event, perception and reduction-, we can ask if and how these notions, in their standard definitions, are able to essentially apprehend (and consequently to express) the multifaceted implications of the phenomenon of violence in its plural dynamics. It is perhaps the particularity and the privilege of all limit-phenomena or limit-situations to force our phenomenological understanding to redefine our very concepts, to enlarge them, to extend their meanings and to reconsider their stakes. If we understand violence in this sense (as a limit-phenomenon or limit-situation), it might have a disrupting role not only in regard to our pre-theoretical everyday life, but also with respect to the theoretical approach of our experience. Not only is violence a brutal test of our embodied vulnerability, lived in a conflictual intersubjectivity and fuelled by an inflamed affectivity, but also the phenomenological conceptuality itself seems to be thoroughly put to test in the very attempt of understanding this peculiar phenomenon. It is as if the phenomenon itself becomes capable of putting into question our own categories meant to grasp it, to describe it, to interpret it, or to explain it. 
When violence is at stake, we encounter not only a powerful tension between the theoretical level (observing, analysing, describing, understanding, contextualizing, interpreting, conceptualizing, theorizing, or explaining violent phenomena) and the experiential level (enduring violence as a passive pole, exerting it as an active pole, or being concretely and directly exposed to violence as a witness), but we also face a kind of reversal: it is not the theoretical approach of violence that dominates the phenomenon, but the phenomenon itself powerfully determines our ways of understanding it.

For instance, in classical phenomenology, perception is taken as the fundamental mode of our consciousness, and all the other possible modalities of our experience within the world-fantasizing or imagining, remembering or anticipating, dreaming or perceiving images - are described as basic modifications of perception. As such, any object whatsoever ("a cube," "the Eiffel Tour," or "an ivory Steinway piano") can be given either "in the flesh," in the direct perceptive experience of an awake and self-aware consciousness, or in various indirect modes, as, for instance, the "same" object I imagine in my phantasy, I remember in memory, I dream in my oneiric life, or I see as an image through the plurality of possibilities of imageconsciousness. However, when we are concerned with the phenomenon of violence, we can wonder if the notion of "perception"- - and the philosophy of consciousness that takes it as starting point-would not be too restrictive to capture this holistic experience. In the lived experience of an actual, real event, we do not simply "perceive" the phenomenon of violence, as we detachedly perceive a cube or a building, distantly apprehending its multiple concordant aspects. We do not only fully participate in this phenomenon, being bodily and affectively immersed within it, but we are especially overwhelmed and overturned by it, and find ourselves unable to operate a coherent synthesis of experience, as is regularly the case in so-called "normal" life. Thus, the phenomenon of violence puts into play a radical-even if only temporary-abnormality of the structures of experience. This abnormality can eventually be described starting from the normative character of the normality of our daily life, which is experientially coherent and cohesive. But violence does not simply inscribe itself into this concrete experiential unfolding of our daily lives, into this existential continuity of our conscious flow, as another type of lived experience among others, as another type of event or as another type of particular situation among others, in a series that is finally coherent. In fact, violence generates a rupture in this flow of life, a brutal discontinuity in the coherent everydayness of our life, a suspension that is equally reflected in the relations the self enters with oneself, the others, and the world as a whole.

In direct or actual experience, violence has, at least for the one who endures it, an overwhelming and crushing presence. Another question arising here is whether it would be entirely appropriate to say that violence occurs "in the flesh" (leibhaft $d a$ ), provided that any intention of the enduring subject is totally outweighed and overflowed in such an excessive experience, and one's own coherence as subject is fatally disturbed. Indeed, it would be difficult to speak in this context of an "adequate perception" in the so-called noetic-noematic correlation. The phenomenon of violence is not, of course, an "object," such as the cube or the building we see on the other side of the street, but it is an excessive event in which two (individual or 
collective) subjectivities - each one anchored in one's own "I can"-are antagonistically engaged, bodily as well as affectively, in a frontal existential collision, in the materiality of their beings. This is why we cannot simply speak of perception here, saying that in a quarrel I "perceive" the fist of the other that strikes me. The shaking character of the experience of violence must therefore be understood starting from different categories, such as "the overwhelming" or "the excessive," since it effectively knocks down the subjectivity and its habitualities. If we put into play the two poles directly involved in the violent clenching (be it symmetrical or asymmetrical), the concept of perception seems too neutral, too detached to account for the phenomenological charge of this experience. Indeed, to say "I perceive that I exert violence on another subject" or "I perceive that the other exerts violence on me" leads us to a rather barren, abstract and rarefied area of meaning, far removed from the facticity of the concrete experience. Only from the position of the third partymore distant and somewhat more protected-we could perhaps say that "I perceive that one fighting another," although here too the idea of perceiving seems unfit to describe this experience, in its affective and empathic charge. And it is precisely the position of the third that allows and gradually makes possible the transition from the experiential (pre-theoretical) level of directly lived violence to the theoretical level comporting various ways of remotely considering it. This is why the main phenomenological access to the question of violence seems to be given by the instance of the witness.

Similar difficulties arise in exploring other modalities of experiencing, the ones that are usually delimited in contrast with the basic perceptual comportment of our consciousness, as modifications thereof. If we also engage memory, phantasy, dream or image-consciousness, the phenomenological analysis of violence becomes a multi-modal approach, discovering a plurality of ways in which violence is given. This manifold givenness of violence can consequently open new topics of phenomenological analysis, such as the mnemonic violence, the phantasmatic violence, the oneiric violence, or the imagistic violence. In each of these instantiations, not only the givenness of violence modifies itself, but also the architectonics of this phenomenon-with its inherent dimensions, its constitutive structures, and its essential possibilities-receives each time a different configuration.

How is violence modulated at the level of memory? In what sense can we phenomenologically approach the violence sedimented in memory? How is a past violence actualized and simultaneously modified through remembering? Here, the phenomenon of amnesia resulting from a radical violence is also relevant, because not only the recollection of violence is significant, but also its total forgetfulness. When remembered, violence is not actually present, is not given "in the flesh," but it is only "presentified" by memory, namely brought to presence in our consciousness without being present itself. The presentified violence is still a real one, but it naturally belongs to the realm of the past, and from there it is brought in my actual present, either voluntarily (as when "I try" to remember what happened) or involuntarily (as when I am suddenly "haunted" by past experiences), or even under constraint (when I am forced, in spite of my will, to confront my own past and to give testimony about 
it). But what exactly and how much of the "content" of the violent experience is presentified by memory, in each of these situations? Can we homogeneously presentify all the fundamental dimensions of violence-such as the antagonistic intersubjective situation, the overwhelming affective burden, and the peculiar bodily involvementor just some traces, be it vividly or vaguely? Indeed, from the fullness of the lived experience, one can presentify only some details of that limit-situation which has brought the subject in the incapacity to synthesize and unify its own experience.

Moreover, this presentification of the experience of violence in memory is distinctly possible for each of the three subjective poles involved. Therefore, the multipolar intersubjective dimension of the phenomenology of violence plays a decisive role here as well. The phenomenological analysis should specifically describe how one remembers (voluntarily or involuntarily) the situation of violence experienced "as a third party" (when one has witnessed the confrontation-be it symmetrical or asymmetrical-between two other people); then, how one remembers the violence experienced "as an active pole" (violence exerted in the first person); and, finally, how one remembers this experience from the position of the one who endured it. In each of these cases, the act of remembering violence bears certain specificities. For instance, the reminiscent act of the perpetrator could be accompanied by regret, remorse or shame, provided that the present re-signifies the past, invalidating it (the past violence having retrospectively acquired the negative meaning of an "evil"). And if this change of meaning does not occur, we have to deal with the impenitence, with the lack of any guilt regarding the violence exerted, with the absence of any remorse, or even with the satisfaction of the exerted violence, thus with the retroactive validation of that violent past (as in satisfied revenge). On the other hand, for the person who endured the violence, its presentification in memory occurring in the traumatic shivering can lead either to the existential blockage of the present, to vengeance, or to redemptive forgiveness. Another meaning of mnemonic violence can occur in an inter-generational dimension, as in situations where violence, conflict and revenge are transmitted from one generation to another, the so-called vendetta.

Violence is also shaped on the level of phantasy. Therefore, we can explore the phenomenological characteristics of phantasmatic violence. For example, I can imagine, through the free exercise of phantasy, that two people are fighting in front of me, aggressing each other. Then, I can change the phantasy situation of the symmetrical violence into an asymmetrical one, and I can imagine that one strikes the other, while the latter is defenceless. I can also change, in the free exercise of phantasy, my position as a third, by putting myself in the skin of the person who endures the violence or in the skin of the person who exerts it. I can make these modifications in phantasy either voluntarily, in a controlled way, as in a "mental experiment," traversing the possible modalities of violence in the level of imagination. But I can also be involuntarily and irrepressibly brought in the free play of phantasy, as in a furious daydream (for example, the phantasmatic lived experience of the one who is seeking revenge, presentifying it in the vindictive imagination: "I imagine that I catch and punish the one who insulted me in traffic," etc.). The violence here is of course unreal, but it is at the same time phantasmatically present in my consciousness. 
We can also speak of oneiric violence. We can therefore ask what kind of experience of violence is constituted on the level of dreaming. The nightmare is indeed an experience of violence, where the dreaming self endures a peculiar violence-consequently being a passive pole-while the harmful pole is either precisely defined (generating fear) or imprecise and unfamiliar (generating horror). We can also have dreams in which the dreamer subject exerts the violence; or we can have dreams in which we place ourselves in the position of the third, "witnessing" the violence between two others clenched in confrontation. But is the dream violence "real" or "unreal," is it "present" or "not present," is it "virtual," "fictional" or "simply phantasmatic"? Surely, for the one who dreams, in the genuine situation of the actual living the dream itself, the violence seems to be as real as possible and also actually present, being experienced both bodily and emotionally. In the awake state of consciousness - when, remembering, we feel relieved and say: "it was just a dream!"we re-signify the initial experience and modify its meaning. Only starting from the positions of the awaken state do we perceive the violence in the dream as being "unreal," reaching the reassuring understanding that we were not "in fact" threatened by any real violence. But in the dream, in the actual experience of the nightmare, that violence seems to us as real as possible, and this is why we go through all kind of affective states correlated with violence: we are afraid, scared, filled with terror or horror. However, in this context, it would be highly important to sharply distinguish between "the violence experienced in the dream" and the modification that memory produces in the awake state, as "a reminiscence of the dreamed violence".

The modalizations of violence through the image-consciousness open a more complex area of analysis, since the imagistic violence is perhaps the most widespread phenomenon in our lived experience. We are confronted here with the task of differentiating phenomenologically between various modalities of imagistic violence, by describing how each image-experience constitutes itself. The manner in which violence appears in and through each imagistic medium (painting or photography, cinema or television, internet or video games, etc.) determines the constitution of the experience of violence as such, depending on the intrinsic characters of the displayed violence (real or fictional, past or present, distant or proximate, etc.). It is a large topic, massively debated within visual studies, media studies, and other related disciplines, where a rigorous phenomenological angle of analysis is more than necessary, justifying the need of a multi-modal phenomenological approach of violence.

\section{$* * *$}

Guided by this multi-modal approach, but without having the pretention to cover all the topics it involves, the papers included in this special issue of Human Studies tackle the problem of violence from a plurality of phenomenological angles, engaging a variety of sources from the phenomenological tradition.

Remus Breazu places the question of violence in the very core of the phenomenological approach, asking if the phenomenon of violence is pertinent for both the transcendental ego and the empirical ego. He emphasizes that violence pertains only to a vulnerable subject and this vulnerability of our embodiment has its limit-situation in mortality and death. Following some fragments in which Husserl 
argues that only the empirical ego is mortal, while the transcendental ego is immortal, Breazu claims that, since vulnerability cannot belong to the realm of the transcendental ego, no violence can ever touch it. Only the empirical ego can endure violence, since only at this level the can vulnerability be taken into consideration as a constituted phenomenon.

In her study aiming to contribute to the dialogue between phenomenology and psychoanalysis, Cătălina Condruz takes as starting point the disintegration of the ego, as it can be described in the case of schizophrenia. She considers a peculiar modification of the intersubjective structure of the phenomenon of violence: mental violence does not involve the others (as agents or patients of violence), but only the ego, being precisely violence against the self. This form of violence can also be found in the field of psychoanalysis, where it is regarded as a "fundamental violence" because it shapes the ego in its early stages of development, without being destructive (as in the case of mental illness), but fundamentally constructive. Focusing on Marguerite Sechehaye's writings, Cătălina Condruz shows that mental violence has its source in a loss of reality and of sense, and interprets the passage from the disintegration of the ego to the reconstruction of the ego-and the transition from abnormality to normality-using Marion's conceptuality, as elevation of a poor phenomenon to a saturated phenomenon.

Cristian Ciocan's article is focused on the question of how affectivity takes shape in the violent encounter, describing the articulation of the three subjective poles involved in the antagonist conflict. This analysis explores firstly the affectivity of the pole exerting violence, tracing the emotional progression from dissatisfaction and indisposition to annoyance and hostile antagonism, and then from anger and fury to the fierceness of the actual violent clash. Secondly, the affective dimension of the pole enduring violence evolves from the fear of the other and comports various modalizations, such as fright, dread and terror, as being terrified in the impossibility to recoil. Finally, the affectivity of the third depends on the character of the witnessed violence, be it symmetrical or asymmetrical, varying from stupor to consternation, from being astonished to being revolted, from indignation to shock.

Paul Marinescu addresses a particular phenomenon placed between violence and non-violence: the act of protest against a certain type of order. Following Ricoeur's phenomenological hermeneutics, Marinescu aims to unfold some of the constitutive layers of the protester's "being-there-against," in particular the bodily presence and the linguistic dimension. The author explores how the expressive body is involved in gestures or postures of protest, such as the fist raised in the air, emphasizing the anamnestic nature of the protester's opposition, as it appears in relation to the supraindividual entity claiming the monopoly of violence: the State. Paul Marinescu also discusses the linguistic utterances emerging during protests, such as slogans, closely examining their specific dynamic of meaning that oscillates from surplus to deficit.

Ciprian Jeler's article is also focused on the act-dimension of violence, arguing for a "non-instrumental" understanding of violence, basing his insight upon a close reading of Jean-Paul Sartre's Notebooks for an Ethics. Jeler shows that the usual instrumental view, such as Arendt's, considers that the criterion distinguishing violent behaviours from non-violent ones refers to the nature of means used toward an end. In contrast, Sartre's view is subtler, since violent behaviour is not given by 
using specific means, but by a particular way of employing them, which is itself based on a modification of the agent's attitude with respect to her/his goals. Jeler illustrates this modified attitude towards the goals in three ways: the non-productive attitude, the counter-productive attitude and, finally, the anti-productive attitude.

Ion Copoeru starts from the necessity of defining the notion of violence, aiming to find a middle ground between the perspectives that use a narrow concept and the theories that operate with a broader notion of violence. In order to hint at an originary meaning of the concept of violence, Copoeru focuses on the specific temporality of violence, indicated by the notion of event, with its characters of discontinuity, interruption, and rupture. He shows that the structure of this phenomenon can be better understood by unearthing its main characteristics: directedness (violence as action directed against someone or something), co-performativity (violence as a response coming from a partner involved in the situation), and de-capabilisation (violence as deprivation of the potentiality of action). ${ }^{1}$

Publisher's Note Springer Nature remains neutral with regard to jurisdictional claims in published maps and institutional affiliations.

\footnotetext{
${ }^{1}$ These studies are parts of the research project entitled The Structures of Conflict: A Phenomenological Approach to Violence (PN-III-P4-ID-PCE-2016-0273), conducted at the Research Institute of the University of Bucharest and funded by UEFISCDI.
} 